\title{
Plasma and Urine Malondialdehyde Levels of Infants with Acute Bronchopneumonia in the Assessment of Oxidative Response
}

Huseyin Dag ${ }^{1}$, Ayşem Kaya ${ }^{2}$, Vefik Arıca ${ }^{1}$, Sadik Sami Hatipoglu ${ }^{1}$, Guner Karatekin ${ }^{1}$ and Habip Gedik ${ }^{3^{*}}$

${ }^{1}$ Department of Children's Health and Diseases Clinic, Okmeydani Training and Research Hospital, Health Sciences University, Istanbul, Turkey

${ }^{2}$ Department of Biochemistry, Istanbul University Cardiology Institute, Istanbul, Turkey

${ }^{3}$ Department of Infectious Diseases and Clinical Microbiology, Bakırköy Sadi Konuk Training and Research Hospital, Istanbul, Turkey

"Corresponding author: Gedik H, Infectious Diseases and Clinical Microbiology Physician, Department of Infectious Diseases and Clinical Microbiology, Bakırköy Sadi Konuk Training and Research Hospital, İstanbul, Turkey, Tel: +90 212414 5309; E-mail: habipgedik@yahoo.com

Received date: Januray 01, 2018; Accepted date: March 03, 2018; Published date: March 09, 2018

Copyright: @ $2018 \mathrm{Dag} \mathrm{H}$, et al. This is an open-access article distributed under the terms of the Creative Commons Attribution License; which permits unrestricted use; distribution; and reproduction in any medium; provided the original author and source are credited.

\begin{abstract}
Objective: Acute lower respiratory tract infections are seen as a major public health problem in many developing countries. This study was carried out in order to evaluate plasma and urine malonyldialdehyde (MDA) levels which represents the lipid peroxidation and hence of oxidative stress in infants diagnosed with acute bronchopneumonia which is a cause of high mortality and morbidity in children.
\end{abstract}

Material and methods: This case-control study was carried out at the department of Paediatrics, Ministry of Health Bakırköy Sadi Konuk Training and Research Hospital in 2005. The patient group comprised of 25 patients who were admitted to the hospital with the diagnosis of acute bronchopneumonia. The control group consisted of 10 healthy children of the same age range who had no pathological findings on physical examination. MDA values of urine and plasma samples were compared between both groups as an oxidative stress indicator.

Results: The mean serum MDA value of the patient group was $3.91 \pm 1.55 \mathrm{micromol} / \mathrm{L}$ and that of the control group was measured as $1.03 \pm 0.1 \mathrm{micromol} / \mathrm{L}$. The difference was significantly higher $(p<0.001)$ in the patient group. The mean first day urine MDA value of the patient group were $1.05 \pm 0.90 \mathrm{micromol} / \mathrm{L}$ and that of the control group was 0.009 micromol/L. The difference was significantly higher $(p<0.05)$ in the patient group. The mean urine MDA value of the patient group was found similar to that of the control group at the third and fifth day of follow up $(p>0.05)$.

Conclusion: The urine MDA values on the first day of follow-up and the plasma MDA values may be used as a parameter in the diagnosis and following-up treatment of oxidative stress in the infants with acute bronchopneumonia.

Keywords: Infant; Bronchopneumonia; Malondialdehyde; Oxidative stress

\section{Introduction}

Acute lower respiratory tract infections are considered to be a major public health problem in many developing countries. In these countries, acute lower respiratory tract infections are among very important reasons of mortality and morbidity in particularly in children under 5 years of age. According to the World Health Organization (WHO) for year of 2015, approximately 1 million children under the age of 5 years have died of pneumonia in the world and this is $16 \%$ of all deaths below 5 years of age. Furthermore, $35-50 \%$ of the hospitalizations due to lower respiratory tract infections were related to pneumonia [1].

According to Turkish Demographic and Health Survey in 2003 (TDHS-2003), the mortality rates (U5MR) were reported to be $37 / 1000$ under-five years of age and $5 \%$ of those were due to respiratory tract diseases. However, according to the TDHS-2013 data, this figure has decreased to $15 / 1000$ [2].
Oxidative stress is caused by oxidant-antioxidant imbalance, which means increase of oxidants or the depletion of antioxidants. In order to preserve the structural integrity of cells and tissues and to fulfil their normal functions, the pursuance of current balance between oxidant and the antioxidant system is very important. The imbalance causes oxidative stress in the organism and results in free radicals and reactive oxygen metabolites (ROM) that cause oxidative damage of the basic structural molecules of the body, such as lipids, proteins, and DNA [3-6]. Oxidative stress is considered to play an important role in the pathogenesis of many lung diseases [7-10]. The by-products of lipid peroxidation that result from various biochemical reactions are usually cleansed by antioxidants. Antioxidants are compounds associated with the effective cleansing of free radicals and the suppression of the effect of ROM and pulmonary antioxidant defense mechanisms in the lungs include both enzymatic and non-enzymatic systems.

The free radicals are very short-lived to direct measurement clinically; therefore indirect indicators are used to measure reactive oxygen species. The measurement of plasma malondialdehyde (MDA) level is used as one of the most sensitive indicators of lipid peroxidation, and hence oxidative stress caused by free oxygen radicals in tissues. It is not specific to any disease [11-13]. 
Citation: Dag H, Kaya A, Arica V, Hatipoglu SS, Karatekin G, et al. (2018) Plasma and Urine Malondialdehyde Levels of Infants with Acute Bronchopneumonia in the Assessment of Oxidative Response. J Infect Dis Med 3: 123. doi:10.4172/2576-1420.1000123

Page 2 of 5

The aim of this study was to assess plasma and urine malonyldialdehyde (MDA) levels which represents the lipid peroxidation and hence of oxidative stress in infants diagnosed with acute bronchopneumonia which is a cause of high mortality and morbidity in children.

\section{Materials and Methods}

This case-control study was carried out at the department of Paediatrics, Ministry of Health Bakırköy Sadi Konuk Training and Research Hospital in 2005. The patient group comprised of 25 patients who were admitted to our clinic after with the diagnosis of acute bronchopneumonia and considered to be eligible for hospitalization. Patients with other pulmonary disease other than acute bronchopneumonia were excluded from the study. The acute bronchopneumonia was diagnosed by considering the detailed anamnesis, clinical findings, and chest X-ray, and laboratory findings. The control group consisted of 10 healthy children who had no pathological findings on physical examination at the same age range. None of the children in the groups had a known immunodeficiency, systemic, or congenital disease. The blood samples were drawn into tubes including $2 \mathrm{ml}$ of $25 \%$ sodium citrate solution from the study group during their hospitalization and also the control group during their visit to the outpatient clinic. The plasma was separated immediately from the blood.
Urine samples were taken from the study group on the 1 st, 3 rd, and 5 th day of hospitalization and once from the control group. The plasma and urine samples have been kept at $-700^{\circ} \mathrm{C}$ until making MDA measurement. MDA was identified spectrophotometrically [14]. Informed consent was obtained from the families of the patients and healthy children. The study project was approved by the local ethics Committee (No: 2005/3).

"SPSS (Statistical Package for Social Sciences) for Windows 10.0" software was used for the statistical analysis in the study. The mean values were presented as mean \pm standard deviation. ANOVA and Turkey's B tests were used for comparing the data. Kruskal Wallis, Mann Whitney U, Fisher Exact test, and Chi-Square tests were used for the analysis. $\mathrm{P}<0.05$ was considered to be statistically significant. Correlation analysis was carried out by using Pearson's correlation.

\section{Results}

A total of 25 patients with acute bronchopneumonia and 10 healthy infants were included in the study. There was no statistically significant difference between the groups in terms of age, gestational birth week, birth weight, birth length, head circumference, number of siblings, and kinship ( $>0.05)$ (Table 1).

\begin{tabular}{|c|c|c|c|}
\hline & Pneumonia group & Control group & $\mathbf{P}$ \\
\hline & $\mathrm{N}=25$ & $N=10$ & \\
\hline Age (months) (mean \pm Standard Deviation $(S D))$ & $6.3 \pm 4.5$ & $6.0 \pm 0.6$ & 0.84 \\
\hline Weight at hospitalization $(\mathrm{gr})($ mean $\pm \mathrm{SD})$ & $6341.7 \pm 1724.8$ & $7824.0 \pm 440.2$ & $0.009^{*}$ \\
\hline Gender (n: \%) Female & $10(40)$ & $5(50)$ & \\
\hline Male & $15(60)$ & $5(50)$ & 0.273 \\
\hline Birth Weight $(\mathrm{gr})($ mean $\pm \mathrm{SD})$ & $2775.60 \pm 726.70$ & $3106.00 \pm 212.40$ & 0.599 \\
\hline Gestation age (week) & $37.84 \pm 3.16$ & $39.40 \pm 1.71$ & 0.18 \\
\hline Devit-3: Yes & $11(44.0)$ & $10.0(100)$ & \\
\hline No & $14(56.0)$ & $0(0)$ & $0.000^{* *}$ \\
\hline Just Breastfeeding-month (mean \pm SD) & $3.06 \pm 1.94$ & $4.35 \pm 0.82$ & $0.001^{*}$ \\
\hline The number siblings $(n)$ & $1.68+1.76$ & $0.6+0.84$ & 0.16 \\
\hline Age of mother (years) & $26.96+5.88$ & $30.80+6.49$ & 0.145 \\
\hline Age of father (years) & $30.16+6.27$ & $35.00+7.39$ & 0.146 \\
\hline Duration of the education of the mother- years (mean; SD) & $2.68 \pm 3.34$ & $6.80 \pm 2.53$ & $0.007^{*}$ \\
\hline Duration of the education of the father-years (mean; SD) & $5.48 \pm 2.71$ & $7.50 \pm 3.63$ & $0.044^{*}$ \\
\hline
\end{tabular}

Table 1: The socio-economic characteristics of the patient group and control group.

However, the mean weight of the study group at hospitalization $(6341.7 \pm 1724.8 \mathrm{~g})$ was statistically lower than that of the control group $(7824.0 \pm 440.2 \mathrm{~g}, \mathrm{p}<0.01)$.
The mean length of breastfed was significantly longer in the control group compared to the patient group (4.35 \pm 0.82 months, and $3.06 \pm$ 1.9 months, $\mathrm{p}<0.001$, respectively). 
Citation: Dag H, Kaya A, Arica V, Hatipoglu SS, Karatekin G, et al. (2018) Plasma and Urine Malondialdehyde Levels of Infants with Acute Bronchopneumonia in the Assessment of Oxidative Response. J Infect Dis Med 3: 123. doi:10.4172/2576-1420.1000123

Page 3 of 5

The fully-vaccination and using Devit-3 rates were found significantly lower in the patient group than the control group $(\mathrm{p}<0.01$; $\mathrm{p}<0.001$, respectively, Table 1$)$.

As shown in Table 1, the educational status levels of the parents in the patient group were statistically lower than those of the control group ( $\mathrm{p}<0.01 ; \mathrm{p}<0.05$, respectively). In the patient group, six $(24 \%)$ of mothers and $19(76 \%)$ of fathers were smoking cigarettes, whereas one $(10 \%)$ of the mothers and $4(40 \%)$ of the fathers were smoking in the control group. No statistically significant differences were observed between the study and control groups in terms of the ownership of the house and having a social insurance $(\mathrm{p}>0.05)$.

\begin{tabular}{|c|c|c|c|}
\hline & Patient group & Control group & \\
\cline { 2 - 4 } & $(\mathrm{n}=25)$ & $(\mathrm{n}=10)$ & \\
\hline & Mean $\pm \mathrm{SD}$ & Mean $\pm \mathrm{SD}$ & $\mathrm{P}$ \\
\hline Hemoglobin $(\mathrm{g} / \mathrm{dL})$ & $10.868 \pm 1.453$ & $11.890 \pm 0.709$ & 0.051 \\
\hline Hematocrit $(\%)$ & $31.24 \pm 3.05$ & $35.70 \pm 1.89$ & $0.000^{* *}$ \\
\hline $\begin{array}{c}\text { White blood cells } \\
\left(10 \mathrm{e}^{3} / \mathrm{uL}\right)\end{array}$ & $18258.80 \pm 9991.16$ & $7074.00 \pm 2001.06$ & $0.000^{* *}$ \\
\hline $\begin{array}{c}\left.\text { Platelet (K/mm }{ }^{3}\right) \\
\text { MCV (fL) }\end{array}$ & $\begin{array}{c}440600.00 \pm \\
\text { M }\end{array}$ & $\begin{array}{c}254000.00 \pm \\
89003.12\end{array}$ & $0.005^{*}$ \\
\hline RDW (\%) & $11.48 \pm 7.47$ & $78.20 \pm 3.61$ & $0.010^{*}$ \\
\hline${ }^{*} \mathrm{P}<0.05,{ }^{* *} \mathrm{p}<0.001$ & $18.24 \pm 3.05$ & $14.90 \pm 1.45$ & $0.004^{*}$ \\
\hline
\end{tabular}

Table 2: The hematologic parameters of the patient group and control group.

\begin{tabular}{|c|c|c|c|}
\hline & Patient group & Control group & \\
\hline & $(n=25)$ & $(n=10)$ & \\
\hline & Mean \pm SD & Mean \pm SD & $\mathrm{P}$ \\
\hline $\mathrm{Mg}$ & $2.24 \pm 0.25$ & $2.03 \pm 0.230$ & 0.011 \\
\hline $\mathrm{P}$ & $4.520 \pm 0.630$ & $5.310 \pm 0.446$ & $0.004^{*}$ \\
\hline $\mathrm{Fe}$ & $13.80 \pm 6.64$ & $50.90 \pm 16.58$ & $0.000^{* *}$ \\
\hline Fe Binding Capacity & $328.36 \pm 72.03$ & $351.00 \pm 104.26$ & 0.079 \\
\hline Serum Protein & $6.840 \pm 0.883$ & $7.110 \pm 0.401$ & 0.018 \\
\hline Albumin & $4.568 \pm 0.551$ & $4.510 \pm 0.363$ & 0.299 \\
\hline MDA SERUM & $3.91 \pm 1.55$ & $1.03 \pm 0.1$ & $0.000^{* *}$ \\
\hline MDA-U1(Product-1) & $1.05 \pm 0.90$ & $0.97 \pm 0.23$ & $0.009^{*}$ \\
\hline MDA-U3 (Urine-3) & $1.02 \pm 0.60$ & & 0.986 \\
\hline MDA-U5(Urine-5) & $1.22 \pm 0.82$ & & 0.927 \\
\hline
\end{tabular}

Table 3: Serum and urine MDA values of the patient group and control group.
The blood count and some biochemical values of the cases were summarized in Tables 2 and 3. The total protein, phosphorus and iron $(\mathrm{Fe})$ averages of the control group were found to be significantly higher than those of patient group $(\mathrm{p}<0.05)$. However, the hematocrit and mean erythrocyte volume of the control group were found to be significantly higher $(\mathrm{p}<0.001)$, the mean of platelet count and red cell distribution width were found to be significantly lower in the control group $(\mathrm{p}<0.05)$.

As shown in Table 3, the mean of plasma MDA value of the patient group was significantly higher than that of the control group $(p<0.001)$. The mean urine MDA value of patient group on the first day of follow-up was found to be significantly higher than that of control group $(\mathrm{p}<0.05)$ and there was no significant increase in urine MDA values of the samples taken on the 3rd and 5th days compared to the first day of follow up.

There was a poor negative correlation between serum MDA levels and platelet and magnesium levels ( $r=-0.396, r=-324$, respectively) (Table 4).

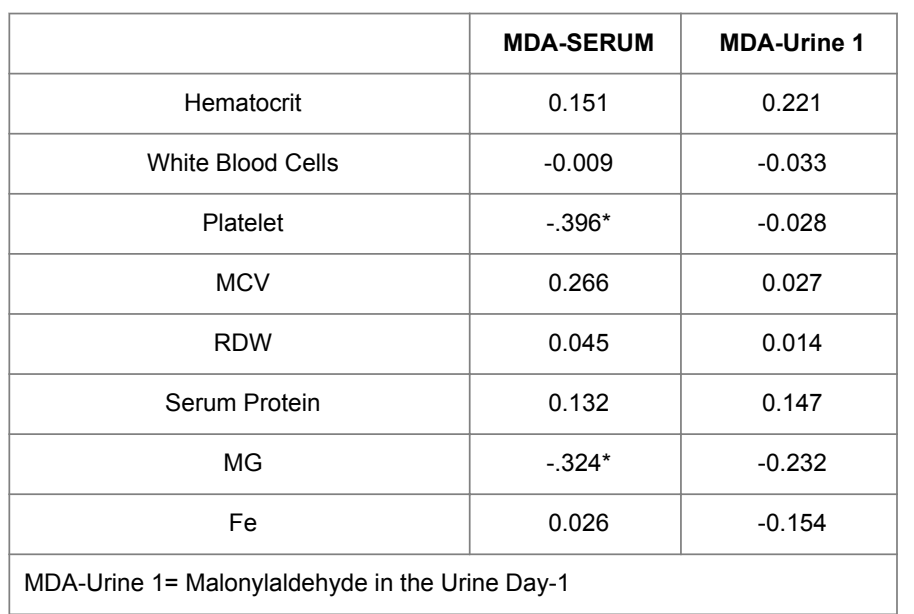

Table 4: The correlation between the serum and urine MDA and the biochemical values.

\section{Discussion}

Lower respiratory tract infections continue to cause significant morbidity and mortality in children and infants, especially in developing countries. Despite a large number of studies on pulmonary diseases and oxidative stress, there are few studies about the role of oxidative damage in infants with acute bronchopneumonia in the literature [7-9,15-17].

Cemek et al. [18] showed that plasma MDA values were found significantly higher in patients with pneumonia (mean age $4.6 \pm 2.1$ years) compared to the control group. In this study, serum ceruloplasmin and total bilirubin values were found to be significantly higher in the patient group compared to the control group, on the other side SOD, GPX (Glutathione peroxidase), $\beta$-carotene, retinol, vitamin $\mathrm{C}$, vitamin $\mathrm{E}$, and reduced glutathione (GSH) levels were found to be significantly lower. Similarly, Cui et al. reported that GPX levels were found to be low in the patients with pneumonia less than 10 years of age [19]. Our study results were similar to those in the study of Cui et al. but different ages and the antioxidant status were not evaluated in our study as well. 
Kolhir et al. [20] found that the level of lipid peroxidation was high in acute and sub-acute periods of pneumonia in adult patients, whereas it was lower during the recovery period. In our study, plasma and urine MDA values were found to be high on the day of diagnosis, but there was no significant increase in the urine MDA values on the 3rd and 5th day of follow-up. Those findings were similar to those of Kolhir et al. [20]. However, we could not assess the serum lipid peroxidation levels that were performed at each day of treatment in that study. Urine and plasma MDA levels may be a parameter to monitor the oxidative stress in patients with acute bronchopneumonia. The urinary excretion of lipid peroxidation products have been reported to increase in the adult patients with moderate asthma due to inhalation allergies as well [21].

While there was a poor negative correlation between plasma MDA values and platelet counts as well as magnesium levels, there was no correlation with serum iron values. A negative correlation was reported to be between oxidative stress and plasma magnesium values in the obese patients pointing out the antioxidant role of magnesium [22].

It was also shown that smoking or exposure to cigarette smoke for a long time played an important role in the imbalance between oxidant and antioxidants $[23,24]$. In our study, no significant difference was found between the children whose parents smoke and those whose parents do not smoke in terms of the serum MDA levels. This may be due to the relatively limited duration of exposure to cigarette smoke and the increased sensitivity of parents with cigarettes.

The fact that the duration of breastfeeding was found to be significantly longer in the control group compared to the patient group in our study suggests that breastfeeding may have an antioxidant effect and may enhance the immune system and protect from the diseases [25].

The study of Aslan et al. [26] reported that there has been an inclination to lipid peroxidation when a person has an iron deficiency anaemia. In our study, there was not found a relation between the iron deficiency anaemia and an increase in the MDA values. However, a general lack of nutrient intake may lead to damage to antioxidant defense mechanisms which may also play a role in the pathophysiology of bronchopneumonia. For this reason, more studies are needed to assess the relationship of nutrition and antioxidant status with a sufficient number of cases.

The use of higher $\mathrm{D}_{3}$ vitamins in the control group may be associated with higher education levels of parents who regularly refer to healthy childhood outpatient clinics that support parents with current medical information and preventive health services. Education in subjects such as child health, balanced nutrition, immunization and access to health services can reduce the mortality rates of infants with acute bronchopneumonia.

\section{Conclusion}

In conclusion, the urine MDA values on the first day of follow-up and the plasma MDA values may be used as a parameter in the diagnosis and following-up treatment of oxidative stress in the infants with acute bronchopneumonia.

\section{Acknowledgement}

There is no conflict of interest.

\section{References}

1. http://www.who.int/mediacentre/factsheets/fs331/en/

2. http://www.hips.hacettepe.edu.tr/tnsa2013/rapor/ TNSA_2013_ana_rapor.pdf

3. Lee IT, Yang CM (2012) Role of NADPH oxidase/ROS in proinflammatory mediators-induced airway and pulmonary diseases. Biochem Pharmacol 84: 581-590.

4. Du Z, Zhang H, Meng X, Guan Y, Wang H et al. (2009) Role of oxidativestress and intracellular glutathione in the sensitivity to apoptosis induced by proteasome inhibitor in thyroid cancer cells. BMC Cancer 9: 56.

5. Paz-Elizur T, Kruspsky M, Blumenstein S, Elinger D, Schechtman E, et al. (2003) DNA repair activity for oxidative damage and risk of lung cancer. J Natl Cancer Inst 95: 1312-1319.

6. Caporaso $\mathrm{N}$ (2003) The moleculer epidemiology of oxidative damage to DNA and cancer. J Natl Cancer Inst 95: 1263-1265.

7. Rahman I, Morrison D, Donaldson K, MacNee W (1996) Systemic oxidative stress in asthma, COPD, and smokers. Am J Respir Crit Care Med 154: 1055-1060.

8. Kumar KV, Das UN (1993) Are free radicals involved in pathobiology, of human essential hypertension. Free Radic Res Commun 19: 59-66.

9. MacNee W (2001) Oxidative stress and lung inflammation in airways disease. Eur J Pharmacology 429: 195-207.

10. Lang JD, McArdle PJ, O'Reilly PJ, Matalon S (2002) Oxidant-antioxidant balance in acute lung injury. Chest 122: 314S-320S.

11. Inder T, Mocatta T, Darlow B, Spencer C, Senthilmohan R, et al. (2002) Markers of oxidative injury in the cerebrospinal fluid of a premature infant with meningitis and periventricular leukomalacia. J Pediatr 140: 617-621.

12. Akisu M, Küllahçioğlu GF, Baka M, Hüsseyinov A, Kültürsay N (2001) The role of recombinant human erythropoietin in lipid peroxidation and platelet-activating factor generation in a rat model of necrotizing enterocolitis. Eur J Pediatr Surg 11: 167-172.

13. Bilgili G, Dizdarer C, Kalkan S, Köse S, Kara Ö, et al. (2005) Factors related to perinatal turnover are related to malondialdehyde concentration of iliac cord blood. Ege Pediatri Bülteni 12: 7-12.

14. Khoschsorur GA, Winklhofer-Roob BM, Rabl H, Auer T, Peng Z, et al. (2000) Evaluation of asensitive HPLC method for the determination of malondialdehyde, and application of the method to different biological materials. Chromatographia 52: 181-184

15. Mihmanlı A, Güneylioğlu D, Özşeker F, Arslan S, Özgel M, et al. (2003) Hastalarda Serbest Oksijen Radikalleri ve Antioksidanların Aktiviteleri. Toraks Dergisi. 4: 264-268.

16. Wood LG, Fitzgerald DA, Gibson PG, Cooper DM, Garg ML, et al. (2000) Lipid peroxidation as determined by plasma isoprostanes is related to disease severity in mild asthma. Lipids 35: 967-974.

17. Vural H, Uzun K, Erel Ü (1999) Antioxidant status and lipid peroxidation in asthma. Solunum Hastalıkları 10: 77-83.

18. Cemek M, Caksen H, Bayiroğlu F, Cemek F, Dede S, et al. (2006) Oxidative stress and enzymic-non-enzymic antioxidant responses in children with acute pneumonia. Cell Biochem Funct 24: 269-273.

19. Cui H, Yin SA, Gao H, Li G (1997) The comparison of selenium status between the children sufferingfrom pneumonia and the normal children from kindergarten. Wei Sheng Yan Jiu 26: 242-244.

20. Kolhir VK, Bykov VA, Teselkin YO (1998) Use of new antioxidant diquertin as an adjuvant in the therapy of patientswith acute pneumonia. Phytotherapy Research 12: 606-608.

21. Dworski R, Roberts LJ, Murray JJ, Morrow JD, Hartert TV, et al. (2001) Assessment of oxidant stress in allergic asthma by measurement of the major urinary metabolite of F2-isoprostane,15F2t-Isop (8-isoPGF2alpha). Clin Exp Allergy 31: 387-390.

22. Morais JB, Severo JS, Santos LR, de Sousa Melo SR, de Oliveira Santos R, et al. (2017) Role of magnesium in oxidative stress in individuals with obesity. Biol Trace Elem Res 176: 20-26. 
Citation: Dag H, Kaya A, Arica V, Hatipoglu SS, Karatekin G, et al. (2018) Plasma and Urine Malondialdehyde Levels of Infants with Acute Bronchopneumonia in the Assessment of Oxidative Response. J Infect Dis Med 3: 123. doi:10.4172/2576-1420.1000123

Page 5 of 5

23. Altuntaş E, Turgut T, İlhan N, Deveci F, Muz MH, et al. (2003) KOAH’lı hastalarda oksidan-antioksidan düzeyleri. Tüberküloz ve Toraks Dergisi 51: 373-379.

24. Diken H, Kelle M, Tümer C (2000) Effects of cigarette smoking on blood antioxidant level and lipid peroxidation. Dicle Tip Dergisi 27: 31-38.

25. Friel JK, Martin SM, Langdon M, Herzberg GR, Buettner GR, et al. (2002) Milk from mothers of both premature and full-term infants provides better antioxidant protection than does infant formula. Pediatr Res 51: $612-618$

26. Aslan M, Horoz M, Çelik H (2011) Evaluation of oxidative status in iron deficiency anemia through total antioxidant capacity measured using an automated method. Turk J Haematol 28: 42-46. 